\title{
ArcheoSciences
}

Revue d'archéométrie

$29 \mid 2005$

Varia

\section{Areas and limits of employment of portable EDXRF equipment for in situ investigations}

Giovanni Ettore Gigante, Paola Ricciardi and Stefano Ridülfi

\section{OpenEdition}

1 Journals

Electronic version

URL: https://journals.openedition.org/archeosciences/488

DOI: 10.4000/archeosciences.488

ISBN: 978-2-7535-1594-9

ISSN: $2104-3728$

Publisher

Presses universitaires de Rennes

Printed version

Date of publication: 31 December 2005

Number of pages: $51-59$

ISSN: 1960-1360

\section{Electronic reference}

Giovanni Ettore Gigante, Paola Ricciardi and Stefano Ridülfi, "Areas and limits of employment of portable EDXRF equipment for in situ investigations", ArcheoSciences [Online], 29 | 2005, Online since 31 December 2007, connection on 01 February 2022. URL: http://journals.openedition.org/ archeosciences/488; DOI: https://doi.org/10.4000/archeosciences.488 


\title{
Areas and limits of employment of portable EDXRF equipment for in situ investigations
}

\author{
Giovanni Ettore GIGANTE*, Paola RICCIARDI* and Stefano RIDOLFI*
}

\begin{abstract}
The use of mobile spectrometers in the archacometric study of ancient artefacts has become a very common practice over the past few years. It docs open methodological questions on the employment of such techniques in a non-destructive manner, i.c. avoiding the damage of the artifact. Some additional methodological questions come by (i) the use of such instrumentation for diagnostic scopes (in which a different approach to the measurement is required) and (ii) the use of the spectrometers in systematic analysis on big number of artefacts, stored in several muscums (during experimental campaigns).

This paper's aim is to discuss some of this questions, on the basis of the experience in the use of mobile (or Field Portable) systems for Energy Dispersive X-ray Fluorescence (EDXRF) spectroscopy that we have harvested in the last years.

Our conclusions mainly regard the precision of measures, which is related both to the positioning of the spectrometer and to the instrument's instability. Also we deal with the more complex problem of the object's matrix not being homogeneous and of how this can affect the response of the measuring system.

Moreover, it is discussed the more general question of the use of portable spectrometers and, consequently, of the meaning one can give to the results so obtained. As a matter of fact the use of such systems, which have an intrinsic analytic potential, in a non-destructive manner, frequently creates ambiguities that have not been, sometimes, taken into account with attention by the investigators.

Finally some ideas are traced on the development of methodologies which favor a better use of such spectroscopic systems for the analysis of ancient artefacts.
\end{abstract}

Résumé : Depuis quelques années les spectromètres mobiles sont de plus en plus utilisés dans l'étude des anciennes ocuvres d'art.

Cette nouveauté ouvre des questions de méthodologic sur les applications de ces techniques non destructives qui évitent d'endommager les ocuvres à étudier.

D'autres arguments de méthodologie peuvent être développés: i) l'utilisation de ces instruments dans un but de diagnostic (pour lequel il est nécessaire d'cnvisager la mesure d'une façon différente), ii) l'utilisation du spectromètre pour réaliser une analyse systématique (pendant les campagnes expérimentales) sur un très grand nombre d'objets conservés dans plusieurs musées.

Le but de cet article est de discuter ces arguments sur la base de l'expérience que nous avons acquis ces dernières années dans l'utilisation des systèmes mobiles or Field Portable (FP) Energy Dispersive X-Ray Fluorescence (EDXRF). Nos conclusions conccrnent principalcment la précision de mesurc, qui est une fonction aussi bien de la position que de la stabilité de l'instrument.

Nous avons aussi affrontć le problème, beaucoup plus complexc, de la matrice non homogène des objets à étudicr, et comment cela peut influcncer la réponse du système de mesure.

En outre nous discuterons la question plus générale de l'utilisation des spectrométres mobiles et, par conséquent, du sens que l'on peut donner aux résultats obtenus.

En fait l'utilisation de ces systèmes qui, avec leurs proprićtés non destructives, ont un potenticl analytique intrinsèque, peut créer des ambiguités qui n'ont pas toujours été attentivement prises en compte par les chercheurs. Finalement nous présentons quelques applications du développement de méthodologies qui pouvaient permettre une meilleure utilisation de ces systèmes de spectroscopie pour analyser les ocuvres d'art anciennes.

Key-words: Energy Dispersive X-Ray Fluorescence Technique, Field Portable Systems, Non Destructive Analysis, Quantitative Analysis of Mctal Artifact.

Mots-clés : Technique de la fluorescence X, spectromètre mobile, analyse non destructive, analyse quantitative de l'objet d'art en métal.

\section{Some remarks on an EDXRF Non Destructive investigation}

In the last two decades the use of mobile or Field Portable (FP) spectrometers, mostly the Energy Dispersive $\mathrm{X}$-Ray Fluorescence (EDXRF) ones, in the archaeometric study of ancient artefacts has become a very common practice as testified by the very large number of papers appeared in the scientific litterature and of the presentations in the main archaeometric conferences.

The use of EDXRF mobile systems in the first steps toward the caracterization of an ancient artefact is commonly judged a precious tool in order to formulate initial hypotheses, to be verified through other kinds of

\footnotetext{
*Department of Physics, University of Rome "La Sapienza", Piazza Aldo Moro, 2, 00186 ROMA, Italy.

giovanni.gigante@uniromal.it
} 
analysis, often destructive. The most attractive thing in this context is the possibility to use the spectrometer in a Non Destructive (ND) manner in order to fulfil the need, often not eludible, not to damage the artifact. It does open methodological questions about the measure, which have sometimes not been probed into with the necessary attention and criticism, especially when non-destructive techniques are used (Gigante et al., 2005).

Many additional questions arise when the portable instrumentation is used with diagnostic purposes, which require a different approach to the measurement. Last but not least the use of these instrument in systematic measurements on large number of artifacts belonging to several museums or collections generates additional methodological problems (Gigante et al., 2003 ; Shackley, 1998). In this paper all these questions will be discussed together with the analysis of the most important sources of errors we experienced in the ND use of EDXRF mobile systems.

The errors one might make, while performing a measure with an EDXRF spectrometer, can be classified in two large groups: conceptual (or methodological) and experimental. These last ones are related to (i) the measuring system and (ii) the procedure adopted during the measure.

A diagnostic procedure is the identification of the nature or the cause of a particular process, which can take place through the detection of one of the components of the examined sample, but which also implies a preliminary knowledge of the process. The discrimination is extremely subtle: a diagnostic test assumes a prior knowledge of what one wants to observe and thus makes it necessary to explicit the diagnostic query in order to avoid performing an useless measure. In the case that the first hypothesis is not verified, the obtained result could produce another diagnostic hypothesis. Anyway, this only happens if there is a good knowledge of the process under identification; the practice of "blind" diagnostic tests is nevertheless very common. In other words the diagnostic approach does not increase the knowledge of the process but it helps verifying if it occurs. An important aspect is that the measure should be systematic and reproducible; in this case the difference with a scientific investigation tends to diminish. A non-destructive measure is almost always repeatable but its reproducibility is limited because the exact repositioning is difficult and the local non homogeneity can change the result of the measure.

The study of an ancient artefact should take into account all of these concepts, since the aim of experimental investigations is frequently not the same as in pure research and in many different applied fields.

Most of all, the principle of minimum intervention, analogous to the one applicable to medical investigation, often determines the choice of a procedure which is less significant from the scientific point of view but nevertheless allows reaching the diagnostic goal of the analysis.

We do understand that these are dangerous issues because their generalization may lead to wrong conclusions. Our practice in the use of spectroscopic systems in the archaeometric field had led us to detect the risk to assign incorrect meanings to the results obtained through ND investigations.

The homogeneity of the sample is often an implicit assumption in the most common analytical techniques; this cannot be true for non-destructive ones because materials, especially ancient ones, frequently show an internal structure due to both production and degradation processes. This sets a limit for the precision obtainable while performing measures on ancient artefacts, unless there be the possibility to find a zone of the object which is meaningful with respect to the investigation and in which the material is homogeneous. A good knowledge of the material's internal structure and of the degradation processes undergone inside it allows improving the methodology and evaluating the degree of precision of the results that can be obtained. The use of micro-analytical techniques is most of the times advantageous, even though an average (macroscopic) composition is a parameter both more significant and more easily usable for an analysis on the single components of the sample.

\section{FP-EDXRF Non-destructive investigations}

In an EDXRF measure we detect the photons coming from a superficial volume of the object in study, which is delimited by the intersection of the incident radiation beam and the detection cone' (fig. 1). This is actually true only if self-absorption is negligible (which is not a frequently satisfied condition), so that the analysed volume has a most regular shape. In fact, on the outer side it coincides with the area lighted by the $x$-ray tube, while on the inner side it is determined by self-absorptions itself, as we shall see later.

The "axial" positioning of the source (fig. 1 and 2) has the clear advantage of reducing the superficial lighted area, and of allowing an easier positioning of the instrument by using simple optical systems for pointing. The traditional "90-degree" geometry (fig. 4a) has the only manifest advantage of slightly reducing the scattering, which is a negligible benefit in the case of investigations on metals and on middle-high atomic number materials in general. Yet it makes pointing more difficult, because the use of intercrossing laser beams to facilitate pointing is indeed difficult.

All positioning errors determine a variation of the examined volume, with respect to an hypothetic optimal one (fig. 3a); they are of different kinds, as shown for example in figures $3 b$ and $3 c$, in which the area lighted by the source is only a part of that from which the fluorescence radiation comes. Still different is the so-called "enhancement" error (fig. 3d) due to a rotation of the sample, which causes the effective examined volume (which is basically the examined surface) to be bigger than it would normally be.

The advantage of using an axial geometry, in which the tube is positioned in front of the surface of the object, is that little displacements of the sample along the axis do

\footnotetext{
' Given the fact that the detector's active surface is not negligible it is better not to speak of a detector's solid angle but to use the term "field of view".
} 

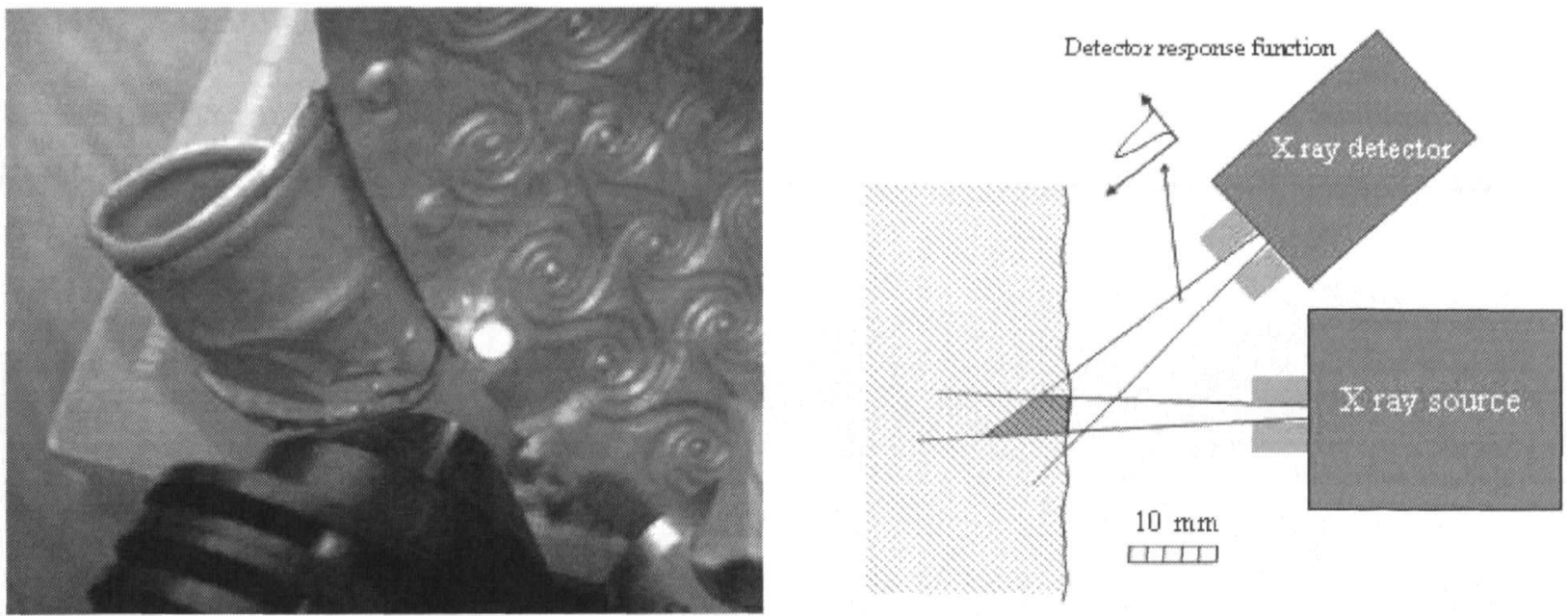

Figure 1: Picture of a spectrometer positioned on a point of a gold artefact. Schematic outline (realistic) of the "axial" geometry. The response function of the detector is also shown in order to visualize the non uniform response of the detector in its field of view.

Figure 1: Spectromètre positionné face à un objet en or. Schéma de la géométrie axiale.

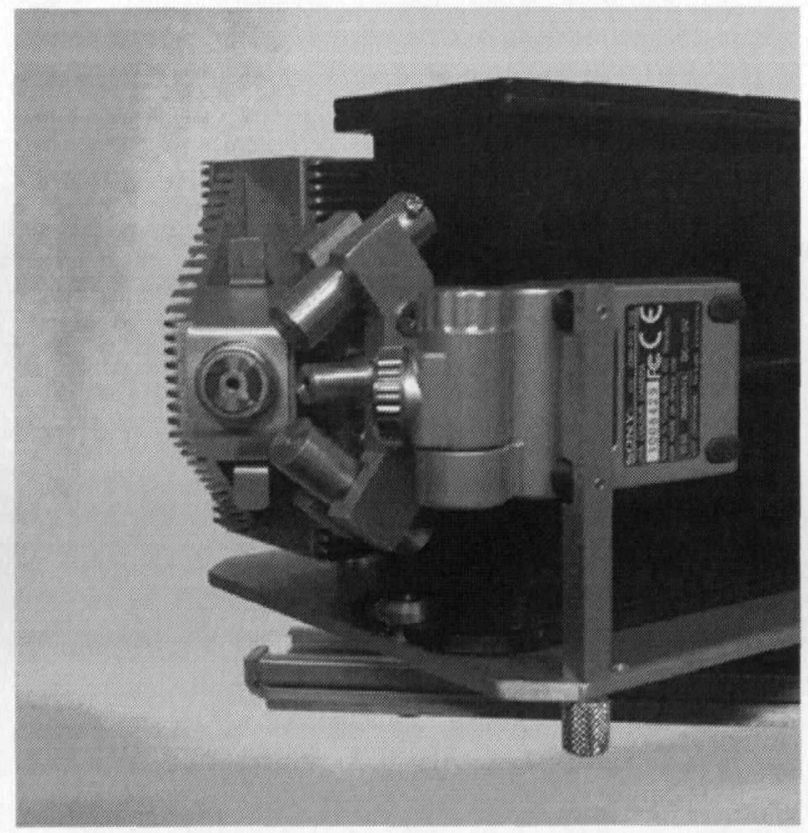

Figure 2: Picture of the pointing system of a FP- EDXRF instrument for non-destructive analysis.

Figure 2: Image du système de positionnement d'un FP-EDXRF pour analyse non-destructive.

not have a great influence on the results of the measure. Outside this "safe" detector-surface distance interval, the probed surface is always smaller than the lighted one (fig. $3 b$ and $3 c$ ). The effect is more visible when using a narrow collimation on the source, so to obtain a thin beam, and a larger one on the detector.

What needs to be remembered is that the error is mostly due to the variation of the surface which is lighted by the incident beam, caused by a not quite perfect positioning of the instrument. On the other hand, the error due to the roughness of the surface itself, which may be large in highly absorbing matrices, does not seem to be eliminable.

The response of the detector is not uniform in its whole field of view, so that the task of quantifying the error induced by its incorrect positioning becomes much harder.

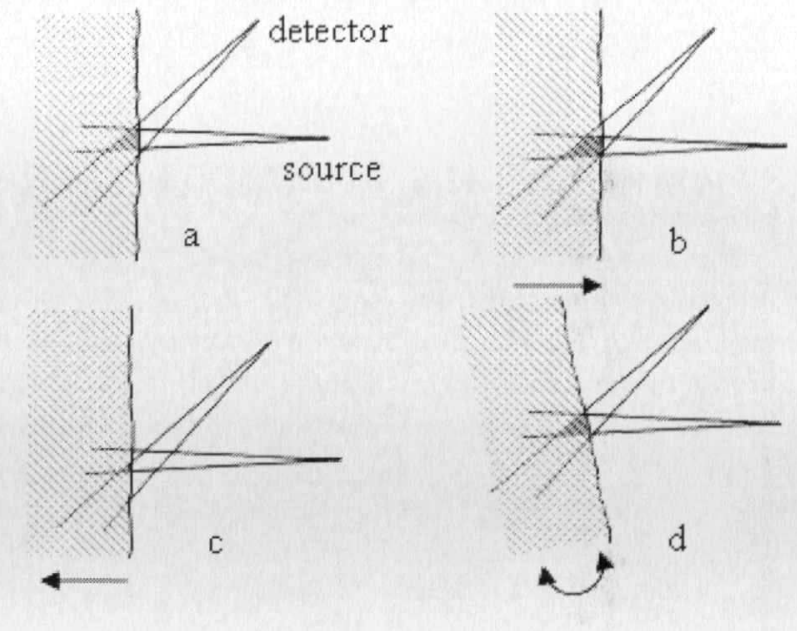

Figure 3: Outline of the possible pointing errors in an axial geometry. Figure 3: Schéma des erreurs possibles de positionnement en géométrie axiale.

Figure $4(a, b, c, d)$ shows that the use of a 90-degree geometry may induce errors similar to those described so far. In this case even a little displacement from the optimal position determines a substantial change of the examined surface.

In all cases of error there is a variation of collected counts with respect to those expected (if the system were correctly positioned), which leads to a non precise evaluation of the weight fractions of the different elements present in the material. Instead, these errors do not affect the estimate of the ratios between the examined elements.

The number of counts in a peak which can safely be assigned to a certain element is proportional to its weight fraction in the examined volume, but it also depends on the self-absorption factor of this same volume. This dependence makes it harder to evaluate the weight fraction of each element; the whole concept is summarized in the following equation: 


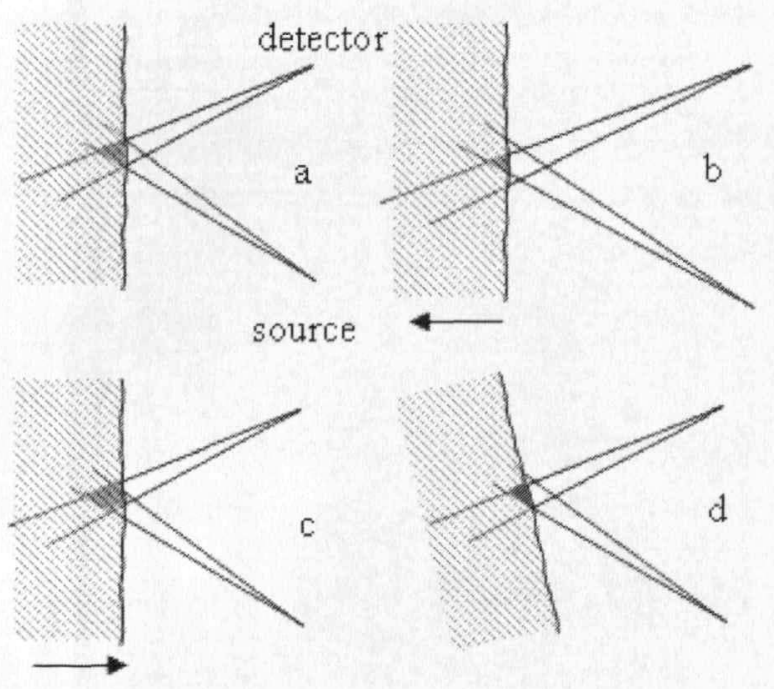

Figure 4: Outline of the possible pointing errors in a 90-degree geometry.

Figure 4 : Schéma des erreurs possibles en géométrie perpendiculaire.

$$
\mathrm{I}_{\mathrm{a}}=\mathrm{A}_{\mathrm{a}} \mathrm{w}_{\mathrm{a}}\left(\frac{1-e^{-\left(\mu_{0}+\mu_{a}\right) \mathbf{x}^{\prime}}}{\mu_{0}+\mu_{a}}\right)=\mathrm{A}_{\mathrm{a}} \mathrm{w}_{\mathrm{a}} \rho \mathrm{x}_{\text {eff }}
$$

in which $\mathrm{A}_{\mathrm{a}}=\mathrm{I}_{0} \mathrm{k} \varepsilon\left(\mathrm{E}_{\mathrm{a}}\right) \mu_{\mathrm{pha}}\left(\mathrm{E}_{0}\right) \omega_{\mathrm{a}, \mathrm{s}} \mathrm{F}_{\mathrm{a}, \mathrm{p}} \mathrm{p}_{1} \quad$ and the other symbols are explained in table 1 .

The absorption coefficients depend on all of the elements which constitute the matrix $\left(\mu_{\mathrm{E}}=\Sigma \mathrm{w}_{\mathrm{i}} \mu_{\mathrm{E}, \mathrm{i}}\right)$ so that the result of the measure may vary with the elemental profile of the sample, even though the weight fraction of the single examined element does not change. This factor may be of critical importance in the case of metals, while it is usually negligible in matrices in which one or two elements strongly prevail, as is the case of organic ones.

In the case of strongly absorbing materials such as metal alloys, stones, and glass, an approximation is almost always valid, so that the following reduced equation can be used:

$$
\mathrm{I}_{\mathrm{a}}=\mathrm{A}_{a} \mathrm{w}_{a} \frac{1}{\mu_{0}+\mu_{a}}=\mathrm{A}_{a} \mathrm{w}_{a} \rho \mathrm{x}_{\text {eff }}
$$

This so-called "infinite thickness" approximation assumes the independence of the measure from the actual thickness of the examined sample, but this is only true with a few limitations. The actual investigated thickness $\left(\mathrm{x}_{\text {eff }}\right)$ shown in figure 5 allows to visualize the real situation for very typical cases of artefacts of historical and artistic interest. Calculations have been performed approximating $\mathrm{x}_{\text {eff }}$ with $\mathrm{x}_{\mathrm{a}}\left(\rho \mathrm{x}_{\mathrm{a}}=1 / \mu_{\mathrm{a}}\right)$, that is disregarding the contribution of the absorption of the incident beam, which leads to an overestimated thickness $\left(\mathrm{x}_{\mathrm{a}} / 2<. \mathrm{x}_{\text {eff }} \leq\right.$ $\mathrm{x}_{a}$ ). In the case of intermediate-absorption matrices (as in oil paintings, for example), the evaluation of errors becomes even more difficult, because the "infinite thickness" approximation cannot be made. The advantage in this case is that the analysis concerns also the elements in the inner layers.

In figure 6 the depth distribution of the emitted Copper $\mathrm{K} \alpha$ line photons in four different matrices is shown.

As already mentioned, the use of ratios of peaks assigned to different elements, all present in the recorded spectrum, is a common practice when the absolute quantification of the weight fraction of the single element is

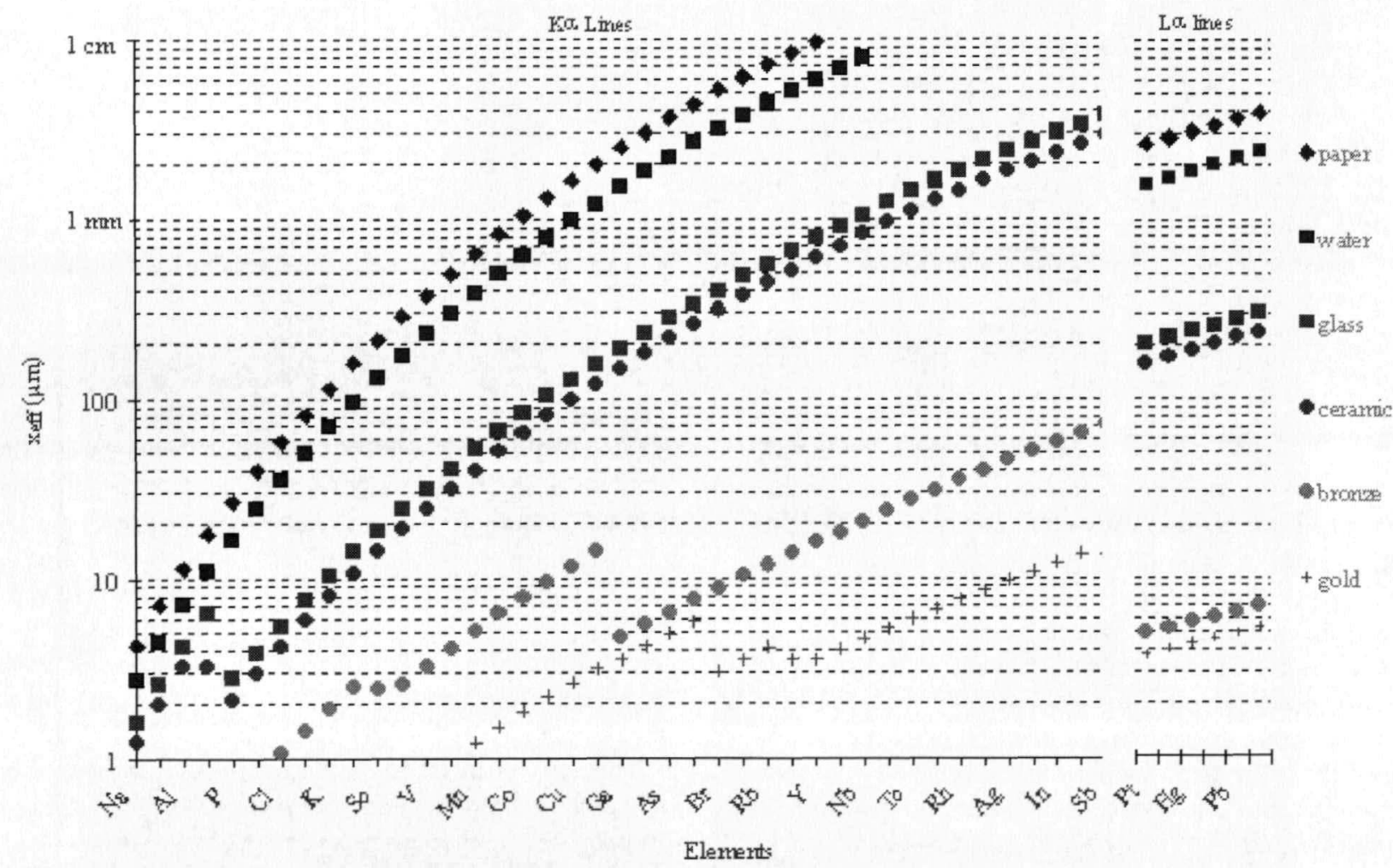

Figure 5: Thickness of the examined layer in the analysis of the principal elements in artefacts of historical and artistic interest having different matrices. Figure 5 : Epaisseur de couche examinée dans l'analyse des principaux éléments dans des objets ayant différentes matrices. 


\begin{tabular}{|c|c|}
\hline $\mathbf{I}_{\mathrm{a}}\left(\right.$ photons $\left./ \mathrm{cm}^{2}-\mathrm{s}\right)$ & $\begin{array}{l}\text { Fluorescent photon fluence rate(number of photons per unit area and time) of } \mathrm{x}- \\
\text { rays of element a; }\end{array}$ \\
\hline$I_{0}$ (photons $\left./ \mathrm{cm}^{2}-\mathbf{s}\right)$ & incident photon fluence rate; \\
\hline $\mathbf{k}$ & efficiency term taking into account for physical and geometrical efficiency; \\
\hline$\varepsilon\left(\mathbf{E}_{\mathrm{a}}\right)$ & intrinsic detector efficiency at the energy of the line of the element a; \\
\hline$\rho$ & physical density of sample \\
\hline$\mu_{\mathrm{ph}, \mathrm{a}}\left(\mathbf{E}_{0}\right)\left(\mathrm{cm}^{2} / \mathrm{g}\right)$ & photoelectric mass attenuation coefficient of element a at incident energy $E_{0}$; \\
\hline$\omega_{\mathrm{a}, \mathrm{s}}$ & fluorescent yield of element a for the shell $\mathrm{s}=\mathrm{K}, \mathrm{L}, \ldots$; \\
\hline $\mathbf{F}_{\mathrm{a}, \mathrm{s}}$ & fraction of photoelectric interactions occurring in the shell s; \\
\hline $\mathbf{p}_{\mathbf{l}}$ & probability that the fluorescence event belongs to the $1=\alpha, \beta, \gamma, \ldots$ line of interest; \\
\hline $\mathbf{w}_{\mathbf{a}}$ & weight fraction of element a; \\
\hline$\mu_{0}$ and $\mu_{\mathrm{a}}\left(\mathrm{cm}^{2} / \mathrm{g}\right)$ & $\begin{array}{l}\text { total mass attenuation coefficients of the sample for incident and XRF energy } \\
\text { respectively; }\end{array}$ \\
\hline
\end{tabular}

Table 1: List of symbols employed in this paper. Tableau 1 : Liste des symboles utilisés dans l'article.

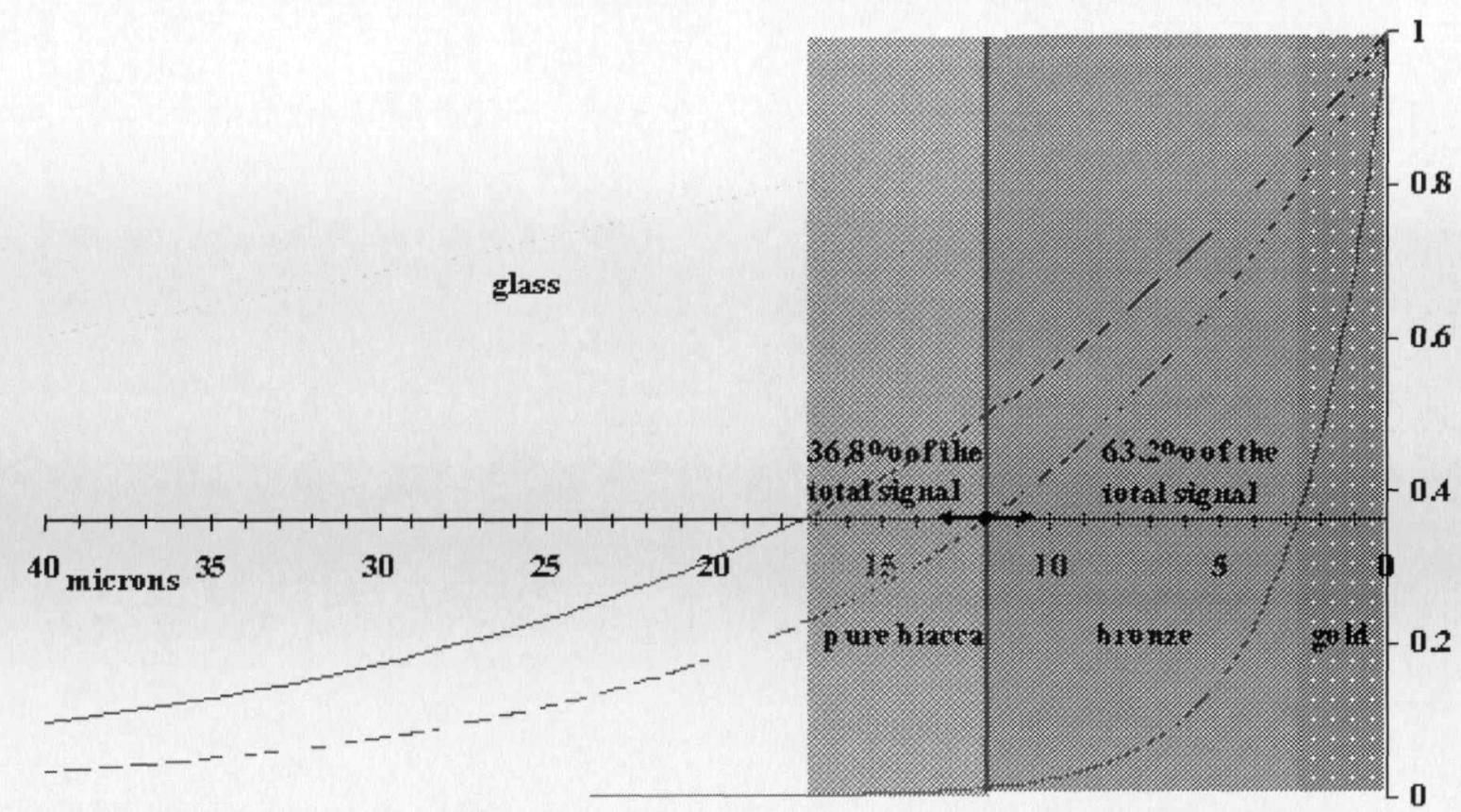

Figure 6: Copper $\mathrm{K}_{\alpha}$ line emitted photon distribution in gold $\left(\mathrm{x}_{\mathrm{eff}}=2.64 \mu \mathrm{m}\right)$, bronze $\left(\mathrm{x}_{\mathrm{eff}}=11.67 \mu \mathrm{m}\right)$, pure biacca (white lead) pigment $\left(\mathrm{x}_{\mathrm{eff}}=17.12 \mu \mathrm{m}\right)$ and glass $\left(\mathrm{x}_{\mathrm{eff}}=79.11 \mu \mathrm{m}\right)$.

Figure 6: Courbe d'émission du cuivre $K_{\alpha}$ dans de l'or $\left(x_{\text {eff }}=2.64 \mu \mathrm{m}\right)$, du bronze $\left(x_{\text {eff }}=11.67 \mu \mathrm{m}\right)$, de la pure biacca $\left(\right.$ plomb blanc) $\left(x_{\text {eff }}=17.12 \mu \mathrm{m}\right)$ et du verre $\left(x_{\text {eff }}=79.11 \mu \mathrm{m}\right)$.

not possible. It is equivalent to the introduction of an internal standard or to the assumption that the sum of weight fractions of the detected elements is one.

We must nevertheless underline the fact that this is certainly a good way to eliminate the error due to the geometrical factor, but also the way of introducing still another error, due to the different self-absorption of secondary radiations. In other words, we can certainly say that the ratio of two peak areas is proportional to the ratio of the weight fractions of the two elements, that is:

$$
\frac{I_{a}}{I_{b}}=k\left(w_{a}, w_{b}, \ldots, w_{i}\right) \frac{w_{a}}{w_{b}}
$$

unfortunately, the constant $k$ depends on the composition of the examined matrix.

\section{FP-EDXRF spectrometry: practice and possible errors}

Experimental errors are, as already mentioned, related to both (i) the characteristics of the measuring system and (ii) the procedure adopted during the measure; they all affect the precision of the obtained results and may also affect the accuracy of the data and thus the reproducibility of the measuring process. Unfortunately, an independent evaluation of the contribution of each source of error on the final variance is not possible; that is, we cannot write the total error as the quadratic sum of the contributes of each source, as in:

(4) $\sigma_{\text {total }}^{2}=\sigma_{a}^{2}+\sigma_{b}^{2}+\ldots$ 
An experimental evaluation of the effect of each source of error has nonetheless been made, by performing several sets of measures on reference gold alloy samples containing different amounts of $\mathrm{Ag}$ and $\mathrm{Cu}$; the statistical spread of each set was then related to the error associated to the different sources of variability that affected those measures.

As for the instrumental error, it is due to both the instability of the $\mathrm{x}$-ray tube and to the detector, which induces an error due to the process of formation of the signal, which follows Poissonian statistics. We reached the conclusion that the $\mathrm{x}$-ray tube needs to be turned on about an hour before starting the first measure (in our case, using a small source), so to drastically reduce fluctuations of the measured spectra. The overall instrumental error has been found to vary between about 0.5 and $3.0 \%$ of the peak areas (table 2); this is true whenever the net area of the peak is large enough to keep the relative statistical error $1 / \sqrt{ }$ A below $3.0 \%$.

\begin{tabular}{|l|l|l|}
\hline $\mathrm{N}^{\circ}$ of set & $\mathrm{A}_{\mathrm{Ag}}$ (counts) & $\sigma_{\mathrm{Ag}} / \mathrm{A}_{\mathrm{Ag}}(\%)$ \\
\hline 1 & 5217 & 2.22 \\
2 & 5367 & 1.02 \\
3 & 5380 & 1.95 \\
4 & 5272 & 0.95 \\
5 & 5280 & 2.98 \\
6 & 5408 & 2.13 \\
\hline
\end{tabular}

Table 2: Ovcrall relative crror of six sets of 10 measures in the same experimental conditions.

Tableau 2 : Erreur totale relative de six jeux de mesures dans les mêmes conditions expérimentales.

\begin{tabular}{|l|l|l|}
\hline$N^{\circ}$ of set & $A_{A g}$ (counts) & $\sigma_{\mathrm{Ag}} / \mathrm{A}_{\mathrm{Ag}}(\%)$ \\
\hline 7 & 6073 & 13.39 \\
8 & 5287 & 8.78 \\
9 & 5835 & 20.45 \\
10 & 6058 & 3.08 \\
\hline
\end{tabular}

Tablc 3: Overall relative crror of four sets of 10 measures with random repositioning.

Tableau 3 : Erreur totale relative de quatre jeux de 10 mesures avec un repositionnement aléatoire.

\begin{tabular}{|l|l|l|}
\hline $\mathrm{N}^{\circ}$ of set & $\mathrm{R}=\mathrm{A}_{\mathrm{Ag}} / \mathrm{A}_{\mathrm{Au}}$ & $\sigma_{\mathrm{R}} / \mathrm{R}(\%)$ \\
\hline 7 & 0.0866 & 1.96 \\
8 & 0.0821 & 1.34 \\
9 & 0.0794 & 2.14 \\
10 & 0.0828 & 1.93 \\
\hline
\end{tabular}

Table 4: Overall relative error on the peak ratio in four sets of measures with random repositioning.

Tableau 4 : Erreur totale relative sur le rapport du pic dans quatre jeux de mesures avec un positionnement aléatoire.
An imprecise positioning of the spectrometer, as discussed in the previous section, can be one of the main source of error. Some experiments were performed in order to quantify this error arriving to the conclusion that a not very accurate positioning of the sample can produce errors that go up to over $20 \%$ of the peak areas (table 3 ); on the other hand, a careful repositioning helps to keep the relative errors almost always below $3.0 \%$ (fig. 7).

Another way to diminish the influence of the geometrical error, is to calculate weight fractions by using the ratios between the net areas of the peaks of interest and the area of a peak chosen as a "reference" (which is usually the main peak of the most abundant and/or most fluorescent element present in the sample, such as the $\mathrm{Au}$ L $\alpha$ peak in gold alloys). This method has the advantage of yielding relative errors still smaller than $3.0 \%$ (table 4 , in which results relative to the same sets of measures as in table 3 are reported), yet it induces problems related to self-absorption, as outlined at the end of the previous section.

In order to speed up the important and delicate process of identifying the elements present in the sample through their characteristic peaks, softwares for the automatic search of peaks in a spectrum have been developed. The basic idea of a spectral analysis is always that the presence of a peak can only be determined on a statistical base by identifying the spectral "window" (range) in which the peak lies, and by verifying the condition for which

(5) $\mathrm{A} \geq b \sqrt{2 \mathrm{~B}}$

where $b$ is 1,2 or 3 depending on the chosen "confidence degree", where B is the background and where the (net) area of the peak $A$ is:

(6) $\mathrm{A}=\sum_{\mathrm{Ch} \text { if }}^{\mathrm{Ch}} \mathrm{N}_{\mathrm{i}}-\mathrm{B}$

and the background B can be calculated with the socalled "trapezium method" as:

$$
\mathrm{B}=\frac{\mathrm{N}_{\text {inf }}+\mathrm{N}_{\text {sup }}}{2}\left(\mathrm{Ch}_{\text {sup }}-\mathrm{Ch}_{\text {inf }}\right)
$$

where $\mathrm{Ch}_{\text {sup }}$ and $\mathrm{Ch}_{\text {inf }}$ are the upper and lower limits of the chosen window.

We can calculate the (net) area of a peak by adding up the counts of each of the channels included in a certain spectral window underneath the peak, after correction for the background. Although this is a very simple way of calculating the background, it turns out to be as precise as much more complex methods, if it is correctly used. In fact, for the "trapezium method" the most critical phase of the process is obviously the choice of the upper and lower limits of the window, whereas for fitting procedures using a polynomial approximation, it is the calculation of background fitting parameters.

In the case of overlapping peaks, when a fitting procedure is always necessary, the obtainable precision is usually smaller, depending on the spectral distance and on the ratio of the areas of the two overlapping peaks.

It will then be possible to identify the peaks by calibrating in energy and comparing the spectrum with the tables which list the characteristic energies of the main emission lines of each element. 


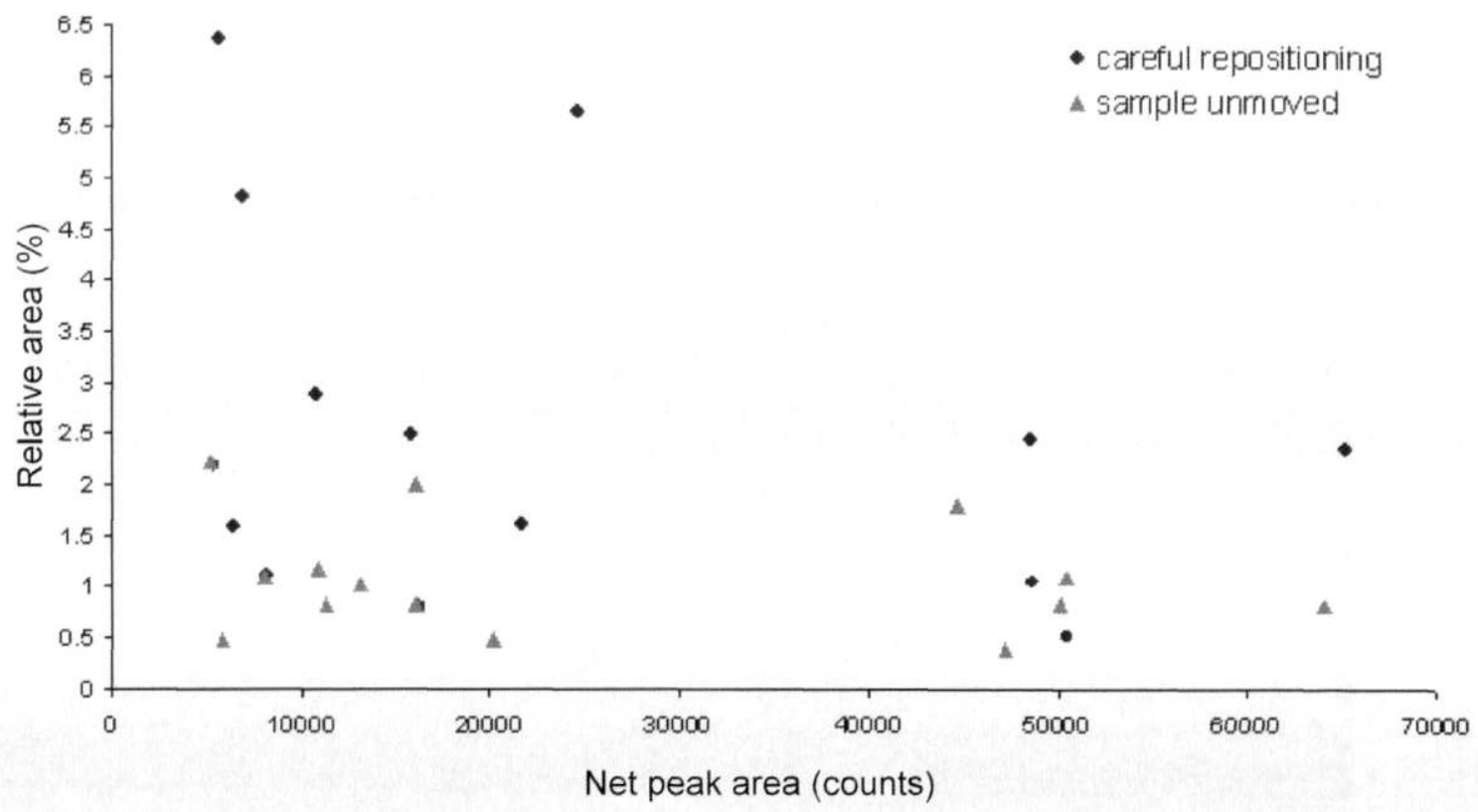

Figure 7: Experimental evaluation of the importance of a careful repositioning, in terms of relative error.

Figure 7 : Evaluation expérimentale de l'importance du repositionnement en termes d'erreur relative.

The use of the fundamental parameters method to perform a quantitative analysis allows evaluating the error to be associated with the results. As is well known, the basic equations of the fundamental parameters method can be solved in an iterative manner. This means that there is no way to write a formula which, a priori, relates the input values (areas of the peaks) with the output ones, which are the amounts of the elements, given in weight percentages. We tried to use a Monte Carlo method to evaluate the error to be associated to the quantitative result. Through a random computation procedure we can build a Gaussian distribution centered around the value of the peak's area, with a sigma which is equal to the error on the area itself. Then we insert the numbers we've just found with this random procedure into the fundamental parameters equations. The quantitative results will then have a Gaussian distribution whose mean value and sigma can be calculated; these two numbers are nothing else than the quantitative result and a valid representation of the error associated to the quantitative analysis through the fundamental parameters method. We've intentionally kept out the errors associated to the parameters which appear in the equations of the method, otherwise the iterative algorithm would be solved too slowly.

Another way to evaluate the error to be associated with the results of a quantitative analysis, is to simply use equation (5) to calculate their statistical spread; it turns out that the whole process of converting peak areas into weight fractions does not induce any further error, so that the overall precision of the measure is no worse than $3.2 \%$ on the weight fraction.

\section{Some example of in situ analysis on precious alloys}

We now show two on going applications to illustrate the possibilities of the method all carried out on golden objects, respectively on Messenian artefacts from the museums of Athens, Olympia, Kalamata, Chora and Pylos in Greece and on golden coins from the Capitoline Coin Cabinet of the city of Rome.

\section{Messenian golden artefacts}

Three experimental campaigns have been carried out on golden objects excavated in Messenia (Greece) by C.W. Blegen and S. Marinatos during the years between 1940 and 1960; most of the tools, jewels and decorative materials have been analysed (Korres et al., 2004a, b, c). The main goal of these campaigns was to study the goldsmith production within a framework of defined chronological and geographical data. The artefacts belong to the collections of the museums of Athens, Olympia, Kalamata, Chora and Pylos. More then 400 objects have been analysed.

The main issue to be addressed in this kind of campaigns is the limited amount of time during which one can perform the measures; in fact, it is not possible to keep the artefacts away from exhibitions for too long. The problem to solve is to acquire and properly store a great quantity of data during the short period of time in which the samples are available, and eventually to organise and present all of the collected data. In these campaigns a database was developed that correlated each measure to the photo of the object analysed, the photo of the exact point of analysis, the EDXRF spectrum, and the quantitative results. As an example in figure 8 we report the file organisation that is behind the data management. There are several different folders: one for the drawings of the artefacts, one for the complete picture of the object (with its catalogue number), one with the pictures of each examined point. There is also a folder with the spectra, one with the quantitative results, and files with documentation on every single analysed artefact.

To give an example of the capabilities of the experimental methodology which has been tuned up, we report 
the numbers of a typical working day during a campaign in a museum. Five or six hours of work allow performing about 70 measures, ten percent of which are used for analysing standard samples, in order to calibrate the instrument and check its stability. If we examine one or two points for each object, at the end of the day we should have acquired, organised and stored all data related to about or over 40 artefacts, each of them unique in history and issues to be solved.

\section{Golden coins from the Capitoline Coin Cabinet of the city of Rome}

The Capitoline Coin Cabinet was established in 1872 following Ludovico Stanzani's bequest of coins and precious gems and includes collections of coins, medals and jewelry belonging to the Municipality. Augusto Castellani, a member of the famous Roman family of goldsmiths who was appointed director of the Capitoline Museums in 1873, generously donated many thousands of coins from the area around Rome representing the different periods of the roman history. Work is in progress to establish modern fakes in the group of coins of the Castellani's donation. Up to now non destructive measu- res have been performed on 62 coins from the numismatic collection. The measure of fineness achieved by non destructive analysis with EDXRF must be crossed with data reported in literature and with numismatic studies of the coins. Figure 9 shows some results on the possibility to detect suspect coins. The silver content seems to be the most sensitive parameter, in fact thirteen coins fall outside the three standard deviation interval. For four of those this fact is confirmed by the copper content.

\section{Conclusions}

The careful discussion of the errors one can perform using a portable EDXRF spectrometer in the ND analysis of ancient metal artefacts led to conclusion that it is necessary to establish an appropriate measuring methodology before starting the measurements. The possibility to increase the contribution of some errors, neglecting for example the influence on the results of the inhomogeneity of the artefact, is, in fact, always present. The usefulness of the FP-EDXRF spectrometers in the archaeometric research is substantial as far as the limits of employment are kept carefully in mind.

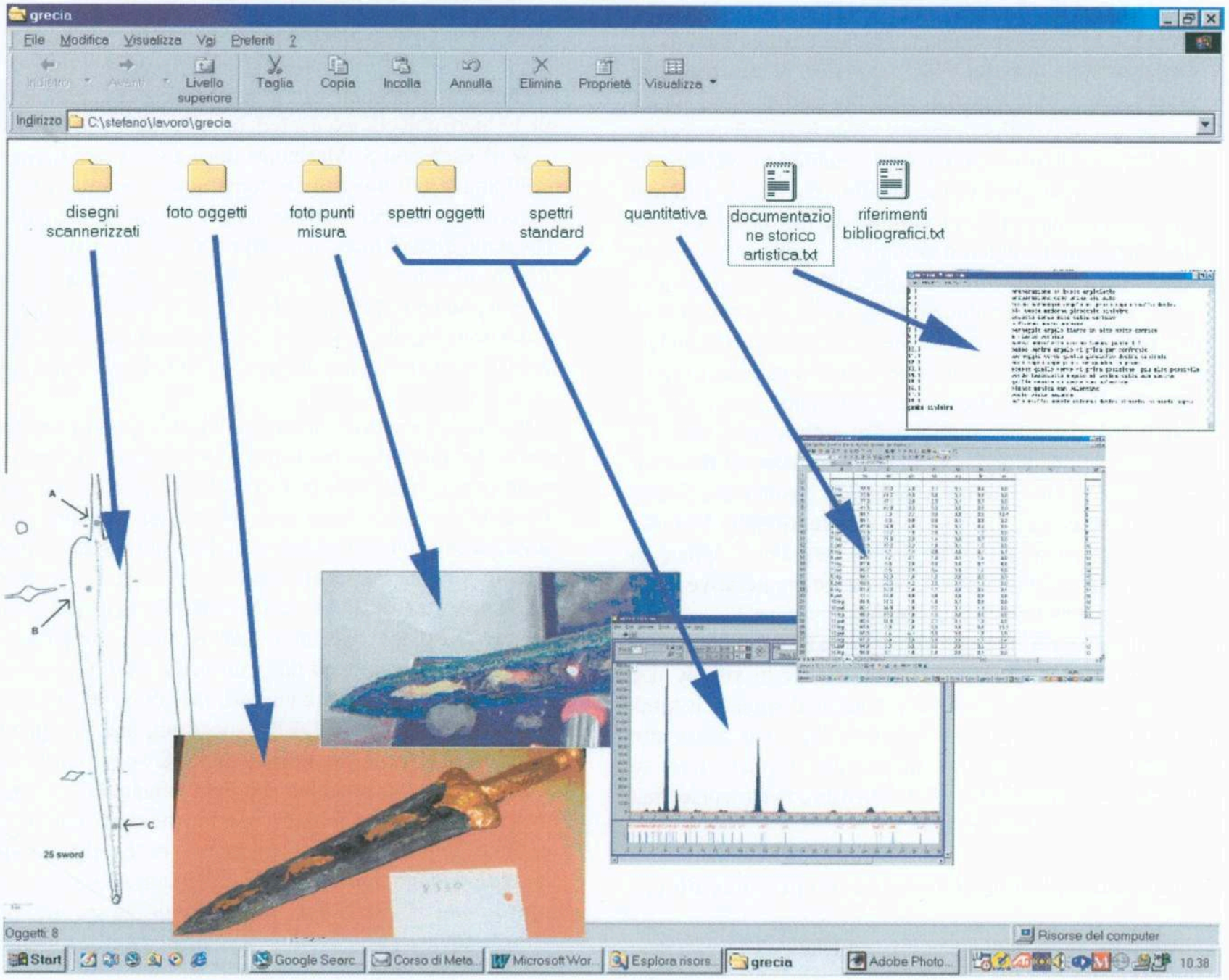

Figure 8: Data organisation during an experimental campaign in several museums.

Figure 8: Organisation des données durant une campagne expérimentale dans différents musées. 


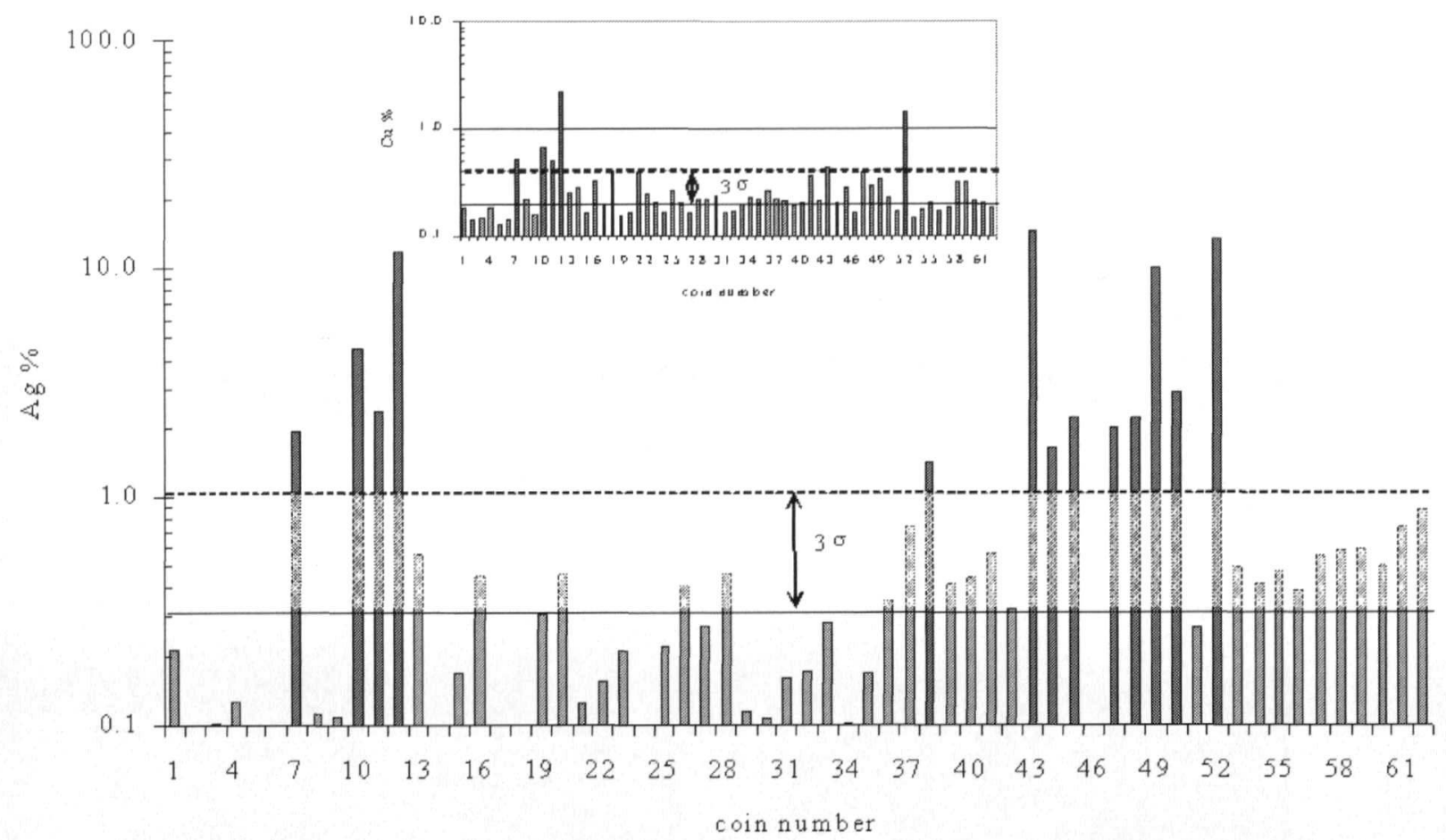

Figure 9: Measured copper and silver weight percentage on 62 coins; 30 coins are $3 \sigma$ apart from average silver percentage. Figure 9: Pourcentage de cuivre et d'argent mesuré sur 62 pièces, 30 pièces sont éloignés de $3 \sigma$ du taux moyen d'argent.

\section{References}

CESAREO, R., GigANTE, G.E., CASTEllano, A. and IWANCKYK, J.S., 2000 - "Portable Systems for Energy Dispersive X-Ray Fluorescence Analysis", In Encyclopedia of analytical Chemistry, R. A. Meyers Ed., John Wiley \& sons, p. 1332713338.

GIGANTE, G.E., GUIDA, G., VISCO, G., RIDOLFI, S., 2003 "Appraisal of the new approach to the archaeometric study of ancient metal artifacts by the use of movable EDXRF equipments", Archaeometallurgy in Europe, proceedings of the $1^{\text {th }}$ International Conference. Milano, vol. II, p. 293-302.

GIGANTE, G.E., RIDOLFI, S., RICCIARDI, P. and COLAPIETRO, M., 2005 - "Quantitative analysis of ancient metal artefacts by means of FP-EDXRF spectrometers: a critical review ", In Cultural Heritage Conservation and Environmental Impact Assessment by Non Destructive Test and Micro-Analysis, R. Van Grieken and K. Janssens Eds., Taylor \& Francis Group, London, p. 1-10.

KORRES, G. S., GIGANTE, G. E., RIDOLFI, S., 2004a - "Archaeometallurgical Studies with a Movable EDXRF Spectrometer on Messenian Gold: The methodological approach" to be published in Archaeometry 2004, proceedings $34^{\text {th }}$ International Symposium, Zaragoza, April 2004.
KORRES, G. S., GIGANTE, G.E., RIDOLFI, S., 2004b - Studio archeometallurgico di manufatti in oro dalla Messenia mediante sistema portatile di EDXRF. Il museo di Chora ed il palazzo di Nestore ad Englianos" proceedings of the II National Conference of Italian Association for Archaeometry, Bressanone Febbraio 2004.

KORRES, G. S., GIGANTE, G.E., RIDOLFI, S., 2004c -"Archeometallurgical Studies with a Movable EDXRF Spectrometer on Messenian Gold: the Archaeological Museums of Athens and Olympia." to be published in Science \& Technology in Archaeology \& Conservation, proceedings of $3^{\text {th }}$ International Conference, Amman - Dead Sea, December 2004.

SHACKLEY, M.S., 1998 - "Precision versus Accuracy in the XRF Analysis of Archaeological Obsidian: Some Lessons for Archaeometry and Archacology" (2002). In Archaeometry 98, proceedings

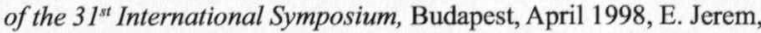
and K.T. Biro Eds., Archaeolingua Central European Series 1, British Archacological Reports, Oxford, p. 805-809. 